\title{
Coexistence of Reverse Capgras Syndrome, Subjective Double and Cotard Syndrome
}

\author{
Azadeh Mashayekhi, ${ }^{1, *}$ and Alireza Ghayoumi ${ }^{2}$ \\ ${ }^{1}$ Department of Psychiatry, Kerman University of Medical Sciences, Kerman, IR Iran \\ ${ }^{2}$ Resident of Traditional Medicine, Faculty of Traditional Medicine, Tehran University, Tehran, IR Iran \\ "Corresponding author: Azadeh Mashayekhi, Department of Psychiatry, Kerman University of Medical Sciences, Kerman, IR Iran. E-mail: psych8961@yahoo.com
}

Received 2014 November 06; Accepted 2014 November 11.

\begin{abstract}
Misidentification syndrome is a condition in which the person thinks that familiar persons have been replaced with other one. Coexistence of some types of this syndrome has been reported with other psychiatric syndromes. In this report, we present a 47year-old married man with coexistence of reverse Capgras and subjective double syndromes with Cotard syndrome. There is no previous report of coexistence of these three forms of delusions in a single case.
\end{abstract}

Keywords: Misidentification Syndrome, Capgras Syndrome, Fregoli Syndrome, Cotard Syndrome

\section{Introduction}

Misidentification syndromes including Capgras, Fregoli, intermetamorphosis and subjective double syndromes. Each syndrome has a core delusion in which the patient misidentifies his or her or other person's identity. The most common and well known of them is Capgras syndrome in which the patient believes that others specially families or loved ones have been replaced by impostered. This syndrome has a rare variant called reverse Capgras delusion in which the patient thinks that he has been replaced with other one. In Cotard syndrome the patient denies his/her existence and in the sever form he/she believes he/she has been died. A paradox regarding immortality exists obviously or hidden in this syndrome [1]. Several reports exist describing coexistence one of misidentification syndromes with Cotard syndrome. In this report we present a case of bipolar mood disorder that had Cotard syndrome associated with reverse Capgras delusion and subjective double in a frame of complex systematic delusion. As far as we know there is no previous report of coexistence of these three forms of delusions in a single case.

\section{Case Presentation}

Represented case is 47-year-old married man with primary educational level. He was living in Kerman city and was referred to OPD Psychiatric hospital of Kerman University of Medical Sciences (Shahid Beheshti hospital) because of irritability, suspiciousness and insomnia. He had been diagnosed as a case of bipolar mood disorder since 7 months prior to his referral date and his symptoms began after his son's car accident and his occupational problems. He experienced a mixed episode of bipolar mood disorder at that time. Some days before his admission he felt that the taste of his food has been changed and he convinced that his wife has been poisoned him several times and he has been died and revived several times while the new person is not the previous person. The revived person is not one person but was two persons at the same time. He convinced one of them is replaced person by agency of intelligence service. No explanations could change his beliefs. He stated that he has two names that one of them has one letter more than another name. Also he said that he has two birth days that one of them is one month and two days later than another one.

He claimed that my double identity helps me to protect myself from probable this woman's conspiracy (the woman was his referral to his wife). The patient had a previous hospital admission 7 months ago in this center with the same symptoms but he discontinued his medications after his discharge. Before that time, he had no psychiatric problems and had normal occupational, interpersonal and social function. He had no history of substance abuse or dependency in his life. His psychiatric family history was negative. In the mental state examination, he had his delusions and inflated self-esteem. He had no depressed or anxious mood and no hallucination. He had hyper talkativeness. His affect was not restricted. His cognition, including memory and triple orientation (orientation to time, place and person), was normal. He 
showed impairment of judgment and had no insight. The physical and neurological examination was unremarkable and brain imaging (brain MRI) was in normal range. Laboratory findings such as liver and kidney function tests, hepatitis, HIV and syphilis were normal. Some improvement occurred with $6 \mathrm{mg} /$ day risperidone and $900 \mathrm{mg} /$ day lithium carbonate.

\section{Discussion}

The coexistence of Capras, Fregoli and Cotard syndromes in a 14 years old girl adolescent was described by Yalin et al. [2]. Another interesting report by Nejad and Kheradmand described a 22 years old man patient with five psychiatric syndromes co-occuring together including lycanthropy (ability of human beings to undergo transformation into a wolf), Cotard syndrome, subjective double, Fregoli (the patient identifies his supposed persecutor in several persons may be different in shape, age and gender) and Dorian Gray syndrome (the patient may think that he remain young but others grow old). In this case no organic causation was found and all of laboratory finding and neuroimaging studies were normal [3]. Several reported about coexistence of misidentification syndromes with Cotard syndrome are indicative of this fact that probably misidentification syndromes and Cotard syndrome may have common root. The symptoms started when stimuli were interpreted wrongly. When it is attributed to external world, misidentification syndrome appears. When the wrong interpreted syndrome was attributed internally Cotard syndrome is formed [4].

The sense of insecurity could be an answer. Patient may use nihilistic delusion to overcome the awful sense of insecurity followed by misidentification delusions. The person convinced that he is no previous himself and has been replaced with others then Cotard syndrome with delusion of immortality and delusion of dying can provide him a safe guard. In one study by Gallego et al. has been revealed that there are some problems in verbal memory tests in Capgras syndrome. Immediate learning, long term memory and long term recognition had been interrupted in patients with Capgras syndrome which demonstrated by neurocognitive examinations [5]. In our presented case the patient stated that he has two names that one of them has a letter more than another name. This statement may have been due to this neurocognitive deficit in verbal memory test. According to Breen et al. model about face recognition visual input lead to structural encoding such as visual code, speech code and expression analysis which form face recognition that interruption in these units lead to Capgras syndrome [6]. In our case, the patient has a reverse
Capgras delusion in which he has a face recognition problem with his face. Mirror illusion is the illusion that person misinterprets his/her image in the mirror. In Matthys et al. study, they found 2 areas uniquely associated with the mirror induced visual illusion: the right superior temporal gyrus and the right superior occipital gyrus [7]. The Capgras delusion has been seen in various psychotic and organic brain diseases but lesions have been generally diffuse although the right temporal lobe has been implicated. A discrete area of brain damage was the anterior part of right fusiform gyrus and a smaller area in the nearby anterior middle and inferior temporal gyri with associated parahyppocampal and hyppocampal atrophy [8]. Since the anatomical site of damage in the Capgras and mirror illusion are the same, we can result that the mirror sign is in the continuum of misidentification syndromes. Some reports have shown the Cotard delusion after brain injury. We suggest that these impairments contributed to his Cotard delusion by heightening of unreality and that the underlying pathophysiology and neuropsychology of the Cotard delusion may be related to other problems involving delusional misidentification. So from all of these finding about similarities in the site of damage in Cotard and misidentification syndrome we can result that Cotard and misidentification syndrome such as Capgras have a same root.

\section{Footnotes}

Authors' Contribution: All authors had equal role in manuscript writing.

Conflict of Interest: The authors declare no conflict of interest.

Funding/Support: Kerman University of Medical Sciences.

\section{References}

1. Enoch D, Ball HN. Uncommon psychiatric syndromes. 4th ed ed. ;2001. pp. 15-36.

2. Yalin S, Valor-Tas F, Guvenir T. The coexistence of Capgras, Fregoli and Cotard's syndromes in an adolescent case. Arch of Neuropsychiatry. 2008;45(4):149-51.

3. Nejad AG, Kheradmand A. Five rare psychiatric syndromes cooccurring together. Neurosciences. 2009;14(1):91-3.

4. Cotard J. Etudes sur les maladies cerebrales et mentales. 2013.

5. Gallego L, Vazquez S, Pelaez JC, Lopez-Ibor JJ. [Neuropsychological, clinical and social issues in two patients with Capgras Syndrome].Actas Esp Psiquiatr. 2011;39(6):408-14. [PubMed: 22127915].

6. Breen N, Caine D, Coltheart M. Models of face recognition and delusional misidentification: a critical review. Cogn Neuropsychol. 2000;17(1):55-71. doi: 10.1080/026432900380481. [PubMed: 20945171].

7. Matthys K, Smits M, Van der Geest JN, Van der Lugt A, Seurinck R, Stam HJ, et al. Mirror-induced visual illusion of hand movements: 
a functional magnetic resonance imaging study. Arch Phys Med Rehabil. 2009;90(4):675-81. doi: 10.1016/j.apmr.2008.09.571. [PubMed: 19345786].

8. Hudson AJ. Misidentification syndromes related to face specific area in the fusiform gyrus. Neurol, Neurosurg Psychiat J. 2000;69(5):645-8. doi: 10.1136/jnnp.69.5.645. 